\title{
Pressure pain threshold in the craniocervical muscles of women with episodic and chronic migraine
}

\author{
A controlled study
}

\author{
Débora Bevilaqua Grossi', Thais Cristina Chaves², \\ Maria Claudia Gonçalves ${ }^{3}$, Viviane Coimbra Moreira ${ }^{4}$, \\ Alexandra Carolina Canonica ${ }^{4}$, Lidiane Lima Florencio ${ }^{4}$, \\ Carlos Alberto Bordini ${ }^{5}$, José Geraldo Specialii, Marcelo Eduardo Bigal ${ }^{6}$
}

\begin{abstract}
Objective: To estimate the pressure pain threshold (PPT) of the craniocervical muscles in women with episodic migraine (EM) $n=15$ and chronic migraine $(C M) n=14$, and in healthy volunteers $(C) n=15$. Method: A blinded examiner obtained the PPT bilaterally, by pressure algometry, for the following muscles: frontalis, temporalis, masseter, trapezius and sternocleidomastoid. ANOVA $(p<0.05)$ was used for statistical purposes. Results: Contrasted to controls, individuals with EM had significantly decreased PPT values for frontal muscle (EM: $2.01 \pm 0.67$ vs. C: $2.85 \pm 0.71$ ), posterior temporalis bilaterally (right and left, respectively) (EM: $2.72 \pm 0.89$ vs. C: $3.36 \pm 0.72$ and EM: $2.60 \pm 1.00$ vs. C: $3.35 \pm 0.85$ ), upper trapezius bilaterally (EM: $2.69 \pm 1.00$ vs. C: $3.49 \pm 0.83$ and EM: $2.54 \pm 0.93$ vs. C: $3.32 \pm 0.97)$ and women with $\mathrm{CM}$ : on frontal muscle bilaterally (CM: $2.16 \pm 0.52$ vs. C: $2.79 \pm 0.71$ and $C M: 2.01 \pm 0.67$ vs. C: $2.85 \pm 0.71$ ) and upper trapezius (CM: $2.66 \pm 0.84$ vs. C: $3.32 \pm 0.97)$, however, it was not verified differences between PPT values between EM and $\mathrm{CM}$ groups. Conclusion: PPT is decreased in women with migraine relative to controls. Future studies should explore this parameter as a biological marker of the disease and a predictor of treatment.
\end{abstract}

Key words: pain threshold, neck muscles, masticatory muscles, migraine disorders

\author{
Correspondence \\ Débora Bevilaqua Grossi \\ Department of Biomechanics Medicine \\ and Rehabilitation of the \\ Locomotor Apparatus \\ Av. Bandeirantes 3900 \\ 14049-900 Ribeirão Preto SP - Brasil \\ E-mail: deborabg@fmrp.usp.br \\ Support \\ São Paulo Research Foundation \\ (FAPESP process 06/56269-4 \\ and 06/56742-1) \\ Received 9 November 2010 \\ Received in final form 18 April 2011 \\ Accepted 3 May 2011
}

\section{Limiar de dor por pressão de músculos craniocervicais em mulheres com migrânea episódica e crônica: um estudo controlado}

Objetivo: Estimar os valores de limiar de dor por pressão (LDP) dos músculos craniocervicais de mulheres com migrânea episódica (ME) $n=15$ e crônica (MC) $n=14$, e em voluntários controles saudáveis $(C) n=15$. Método: $O$ LDP foi obtido bilateralmente por examinadores cegos através da algometria de pressão nos seguintes músculos: frontal, temporal, masseter, trapézio e esternocleidomastóideo. Para análise estatística foi utilizada a ANOVA ( $p<0.05)$. Resultados: Em relação aos controles, pacientes com ME

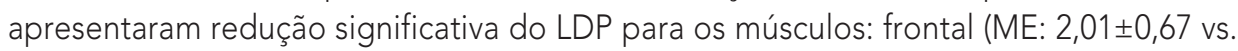
C: $2,85 \pm 0,71$ ), temporal posterior bilateralmente (direito e esquerdo, respectivamente) (ME: $2,72 \pm 0,89$ vs. C: $3,36 \pm 0,72$ e ME: $2,60 \pm 1,00$ vs. C: $3,35 \pm 0,85$ ), trapézio superior bilateralmente (ME: $2,69 \pm 1,00$ vs. C: $3,49 \pm 0,83$ e ME: $2,54 \pm 0,93$ vs. C: $3,32 \pm 0,97$ ) e mulheres com MC: no músculo frontal bilateralmente (MC: $2,16 \pm 0,52$ vs. C: $2,79 \pm 0,71$

\footnotetext{
School of Medicine at Ribeirão Preto (FMRP), University of São Paulo (USP), Ribeirão Preto SP, Brazil: ${ }^{1}$ Professor. Department of Biomechanics Medicine and Rehabilitation of the Locomotor Apparatus; ${ }^{2}$ Ph.D. Department of Biomechanics Medicine and Rehabilitation of the Locomotor Apparatus; ${ }^{3} \mathrm{MSc}$. Department of Biomechanics Medicine and Rehabilitation of the Locomotor Apparatus; ${ }^{4}$ Graduation Student. Phisical Therapy Course; ${ }^{5}$ Professor. Department of Neuroscience and Behavioral Sciences; ${ }^{6} \mathrm{Head}$ of the Merck Investigator Study Program and Scientific Education, Office of the Chief Medical Officer, Merck inc, United States.
} 
e MC: $2,01 \pm 0,67$ vs. C: $2,85 \pm 0,71$ ) e trapézio superior (MC: $2,66 \pm 0,84$ vs. C: $3,32 \pm 0,97$ ). Entretanto não foram verificadas diferenças entre os valores de LDP entre os grupos ME e MC. Conclusão: O LDP mostrou-se reduzido em mulheres com migrânea episódica ou crônica em relação aos controles. Em estudos futuros, esse parâmetro pode ser estudado como marcador da migrânea e indicador de efeito de tratamento.

Palavras-chave: limiar da dor, músculos do pescoço, músculos mastigatórios, enxaqueca.

Headache is an almost universal experience. Among the recurrent forms of headache, migraine affects around $18 \%$ of the women in adult population in the United States of America ${ }^{1}$.

Migraine is currently conceptualized as a chronic condition with episodic attacks ${ }^{2}$ with the potential for progression, meaning that in some individuals, migraine evolves into a stage in which patients have headaches on more days than not, a condition called chronic migraine $(\mathrm{CM})^{3}$.

Prolonged nociceptive input from the periphery may result in central sensitization of the incoming stimuli ${ }^{4}$ and this may be of relevance to migraine ${ }^{5}$. In migraine, central sensitization is associated with refractoriness to treatment ${ }^{5}$ and is a risk factor for chronic migraine ${ }^{6}$. If that is so, it may be speculated that muscle disorders may, per se, be a risk factor for migraine progression to a chronic condition ${ }^{7}$, since they may predispose to central sensitization. The sensitization of pain pathways may increase muscle tenderness in migraineurs ${ }^{8}$, or indeed muscle tenderness may contribute to central sensitization ${ }^{9}$. Peripheral and central sensitization may be estimated by using pressure pain thresholds (PPT) $)^{10}$.

The results of pain threshold in migraine populations are contradictory $y^{9,11,12}$ and have not used algometry. Quantitative Sensory Test (QST) studies suggested that pain threshold is decreased in CM relative to Episodic Migraine (EM) and to controls ${ }^{13}$. Although QST is considered to be the gold standard for pain assessment, it assesses skin sensitivity and not muscle tenderness, therefore not considering the possible peripheral contribution to the chronification mechanism.

Accordingly the objective of this study was to evaluate the craniocervical PPT values in women with EM and $\mathrm{CM}$, relative to controls.

\section{METHOD}

\section{Subjects and overall description}

During a 10-month period, women from 20 to 60 years were randomly selected at a University-based headache outpatient clinic. Our sample consisted of 44 women, being 15 (36.3 \pm 10.3 years) with EM without aura, 14 (38.0 \pm 10.4 years) with CM (also evolving from migraine without aura) and 15 women (39.9 \pm 10.5 years) without current or past history of EM or CM. For a sample size of 42 volunteers, it was verified a power of $0.85, \alpha=0.05$ and effect size of 0.40 (medium effect). It was calculated considering the mean PPT values for frontal muscle. Migraine was diagnosed according to the Second Edition of the International Classification of Headache Disorders (ICHD-2) ${ }^{14}$. For CM diagnosis we have used the criteria of Silberstein-Lipton for transformed migraine ${ }^{3}$. These criteria require headaches 15 or more days per month, past history of episodic migraine and a history of increasing headache frequency. We elected to use the term CM, since studies show that both criteria have $93 \%$ of agreement ${ }^{15}$ and to avoid future nomenclature confusion. Diagnoses were assigned by a headache specialist before the PPT procedure. Controls $(\mathrm{C})$ volunteers, EM and CM patients could not have a diagnoses or complaint of chronic musculoskeletal painful conditions ${ }^{12}$. The control group was selected among people accompanying patients and from the hospital staff ${ }^{10}$.

Exclusion criteria were: other primary headaches, use of analgesic medication over the 24 hours before the evaluation with pressure algometry ${ }^{10,16}$ medication overuse headache, women who reached a PPT value above the maximum permitted by the apparatus $(20 \mathrm{~kg})$ during calibration (palpation of the thenar region) ${ }^{17}$ and women diagnosed with neuropathic pain ${ }^{11}$.

The volunteers provided written consent to take part in the research, and the project was approved by the Ethics Committee on Research of the Clinics Hospital from the Faculty of Medicine of Ribeirão Preto.

\section{Procedures}

PPTs were measured using a digital manual dynamometer (DDK-10, Kratos) adapted for algometry evaluation ${ }^{17}$. The measurement interval of the device ranges from 0 to $29 \mathrm{~kg}$, with a precision of $0.001 \mathrm{~kg}$. A rubber disk measuring $1 \mathrm{~cm}^{2}$ was adapted to the metal point of the device to avoid any harm ${ }^{18}$.

A first examiner screened and forwarded the volunteers to the other two examiners ( 2 and 3 ), who performed algometry after the medical visit. Examiners 2 and 3 performed data collection and Intra and Interrater Reliability of Pressure Algometry. They were blinded to the diagnoses of the subjects. They had been previously trained (15 hours) to apply a constant pressure speed of 
approximately $1.0 \mathrm{~kg} / \mathrm{cm}^{2} / \mathrm{s}$ and correctly position the metal point of the device perpendicular to the evaluated anatomical surfaces. A digital metronome, with frequency of $1 \mathrm{~Hz}$, was used in all evaluations for both examiners with the purpose to provide audio feedback and standardization of the pressure application speed ${ }^{17}$.

During a training session, PPT was obtained on the thenar region of the examiner's right hand, and later on the volunteer's hand, in the same region ${ }^{17}$. Subjects were informed that the evaluation had the objective to determine the pain threshold, and not tolerance to pain, an evaluation section followed.

The PPT values were then obtained bilaterally for the following anatomic points, previously located and marked $^{19}$ :

- Frontal muscle $(2 \mathrm{~cm}$ above the surfacing of the supra orbital branch of the trigeminal nerve $)^{19}$;

- Anterior temporalis muscle (the most prominent and anterior point identified by manual palpation during maximal dental clenching ${ }^{20}$;

- Medium temporalis muscle (located $2 \mathrm{~cm}$ to the lateral rim of the eyebrow $)^{20}$;

- Posterior temporalis muscle (upper fibers behind and straight above the ear, identified by manual palpation during maximal dental clenching ${ }^{20}$;

- Masseter muscle (origin: anterior rim of the surface portion of the muscle; insertion: lower most prominent region identified by manual palpation during maximal dental clenching, and belly: the mid-point between the origin and the insertion);

- Trapezius (insertion: the point immediately below the occipital bone, located in the sub-occipital region; upper fibers: mid-point between the spinous process $\mathrm{C} 7$ and the acromion);

- Sternocleidomastoid muscle (upper portion: fibers below the mastoid process) ${ }^{21}$;

- Right thenar region (used as control) ${ }^{17}$;

- Pressure algometry on the different studied muscles was applied in a random sequence ${ }^{19}$, and the PPT levels were obtained in three consecutive series bilaterally ${ }^{11}$.

\section{Intra and interrater reliability of pressure algometry}

To verify the intra and interrater reliability of the pressure algometry procedure, five women without a history of headache and other painful conditions ${ }^{12}$ were evaluated on the same day for interrater reliability ${ }^{19}$ and after one week for the intrarater reliability ${ }^{22}$. The examiners were blinded to the PPT values obtained for each volunteer in the different evaluations.

\section{Data analysis}

To verify the agreement between intrarater and interrater of PPT values, the intraclass correlation coefficient
(ICC) was used and they were collected in five patients randomly selected from the control group. The ICC values were classified as follows: $<0.4$ : poor reliability; 0.4-0.75: moderate reliability; $>0.75$ : excellent reliability ${ }^{23}$.

For PPT values, we first averaged the mean of the three independent measures obtained for each of the three groups (C, EM, CM). Data demonstrated normal distribution by the application of Shapiro Wilk's W test.

Groups were compared using Analyses of Variance (ANOVA), Duncan post hoc test, $\mathrm{p}<0.05)$. SPSS package (version 14) was used for statistical analysis.

\section{RESULTS}

\section{Clinical characteristics}

Table 1 summarizes the main clinical characteristics of participants. For EM, onset of migraine happened from 1 to 31 years $(15.9 \pm 11.4$ years) before the study. Five women $(33 \%)$ reported their headache attack most often occurred bilaterally and nine (67\%) reported that it was unilateral.

In the CM group $(38 \pm 10.4$ years $)$, the headache history ranged from 4 to 40 years (22.1 \pm 10.7 years). Seven volunteers (50\%) in the CM group reported most of their headache attacks being bilateral. All individuals with CM and 13 (86.6\%) with EM were using prophylactic medications.

Table 1. Clinical characteristics of subjects with CM (chronic migraine) and EM (episodic migraine).

\begin{tabular}{lcc}
\hline & CM & EM \\
& $\mathrm{n}=14$ & $\mathrm{n}=15$ \\
\hline $\begin{array}{l}\text { Subjects' age (years) } \\
\quad \text { Mean } \pm S D\end{array}$ & $38 \pm 10.42$ & $36.27 \pm 10.33$ \\
$\begin{array}{l}\text { Headache history (length in years) } \\
\text { Mean } \pm \text { SD }\end{array}$ & $22.14 \pm 10.68$ & $15.87 \pm 11.42$
\end{tabular}

Days from the last

episode of headache

Mean \pm SD

$1.56 \pm 3.91$

$14.29 \pm 23.94$

Frequency of episodes

(days/month)

Mean士SD

$22.8 \pm 6.74$

$4.07 \pm 3.20$

Localization of the headache

$\begin{array}{lcc}\text { Unilateral L } & 4(28.5 \%) & 3(19 \%) \\ \text { Unilateral R } & 3(21.4 \%) & 2(14 \%) \\ \text { Bilateral } & 7(50 \%) & 10(67 \%) \\ & 14(100 \%) & 13(86.6 \%)\end{array}$

medication (number of

subjects in each group)

SD: standard deviation; L: left; R: right; $\mathrm{n}$ : sample size. 
Table 2. Mean Intraclass Correlation Coefficient (ICC) values for intra and interrater reliability of PPT values $(n=5)$ on both sides of the face.

\begin{tabular}{|c|c|c|c|c|}
\hline \multirow[b]{3}{*}{ Muscle } & \multicolumn{2}{|c|}{ Right side } & \multicolumn{2}{|c|}{ Left side } \\
\hline & \multicolumn{4}{|c|}{ Mean ICC } \\
\hline & $\begin{array}{l}\text { Reliability } \\
\text { intrarater }\end{array}$ & $\begin{array}{l}\text { Reliability } \\
\text { interrater }\end{array}$ & $\begin{array}{l}\text { Reliability } \\
\text { intrarater }\end{array}$ & $\begin{array}{l}\text { Reliability } \\
\text { interrater }\end{array}$ \\
\hline Frontal & 0.74 & 0.90 & 0.93 & 0.96 \\
\hline Anterior temporalis & 0.94 & 0.88 & 0.98 & 0.96 \\
\hline Medium temporalis & 0.95 & 0.90 & 0.99 & 0.97 \\
\hline Posterior temporalis & 0.93 & 0.97 & 0.99 & 0.96 \\
\hline Masseter - Origin & 0.91 & 0.83 & 0.95 & 0.84 \\
\hline Masseter - Belly & 0.91 & 0.91 & 0.93 & 0.91 \\
\hline Masseter - Insertion & 0.98 & 0.82 & 0.85 & 0.89 \\
\hline Trapezius - Insertion & 0.98 & 0.99 & 0.99 & 0.93 \\
\hline Trapezius - Upper & 0.96 & 0.97 & 0.98 & 0.93 \\
\hline SCM Insertion & 0.98 & 0.98 & 0.96 & 0.92 \\
\hline
\end{tabular}

SCM: sternocleidomastoid.

\section{ICC values for intra and interrater reliability}

The PPT values obtained by pressure algometry (Table 2) showed excellent ICC levels for intra and interrater reliability for all assessed points, except for the point on the right frontal muscle, which presented moderate ICC value for intra rater reliability $(\mathrm{ICC}=0.74)$.

\section{PPT values as a function of headache status}

There were significant differences between groups $(\mathrm{F}=37.83 ; \mathrm{p}<0.001)$ regarding the PPT values. Table 3 presents the mean and standard deviation for each site assessed.

Contrasted to controls, individuals with EM had significantly decreased PPT values $(\mathrm{p}<0.001)$ for the following muscles: left frontal (EM: $2.01 \pm 0.67$ vs. C: $2.85 \pm 0.71$ ), right and left posterior temporalis (EM: $2.72 \pm 0.89$ vs. C: $3.36 \pm 0.72$ and EM: $2.60 \pm 1.00$ vs. C: $3.35 \pm 0.85$, respectively) and right and left upper trapezius (EM: $2.69 \pm 1.00$ vs. C: $3.49 \pm 0.83$ and EM: $2.54 \pm 0.93$ vs. C: $3.32 \pm 0.97$, respectively). As compared to controls, women with CM had significantly decreased PPT values on the right and left frontal muscles (CM: 2.16 \pm 0.52 vs. C: $2.79 \pm 0.71$ and CM: $2.01 \pm 0.67$ vs. C: $2.85 \pm 0.71$, respectively) and left upper trapezius muscle (CM: $2.66 \pm 0.84$ vs. C: $3.32 \pm 0.97)$. However, in contrast analyses, it was not verified differences between EM and CM groups for all sites assessed (Duncan post hoc analysis, $\mathrm{p}<0.05$ ).

\section{DISCUSSION}

Few controlled studies used PPT to estimate sensitization of pain pathways in migraine. We found a significant difference between EM and CM, relatively to controls. We found no difference between EM and CM.
Our data are supported by previous studies ${ }^{9,24}$ suggesting that PPT values may map onto migraine biology, being a marker of migraine, but not a marker of headache frequency.

Diffuse or generalized hypersensitiveness to pain is more likely to be caused by changes in the central pain modulation ways ${ }^{25}$ specifically the central sensitization involving the trigeminal nucleus caudalis ${ }^{26}$. Burstein ${ }^{5}$ has proposed that allodynic responses reflect central sensitization at the trigeminal nucleus (facial allodynia) and at the thalamus (extra-cephalic allodynia).

Prolonged nociceptive input from the periphery may be associated to the onset of central sensitization, may exacerbate already established central sensitization, and may impair supraspinal pain modulation, since the hyperexcitability could contribute to an amplification of the nociceptive signal coming from the periphery ${ }^{4,27}$. As a result peripheral nociceptive inputs from the face and cervical sites, contributing or not to central sensitization may have influenced the lower PPT values showed in EM and CM groups.

Considering the contribution of peripheral nociceptive input, the reduction in PPT of masticatory and neck muscles for both groups could be explained by a relationship between trigger points on these sites and migraine. Corroborating our hypothesis, Olesen ${ }^{28}$ reported and discussed a theory about triggers points and the onset of migraine attacks. According to the model, perceived pain (headache) intensity is determined by the sum of nociception from cephalic arteries and pericranial myofascial tissues converging upon the same neurons and integrated with supraspinal effects (usually facilitating). Vascular input predominates over myofascial input in 
Table 3. Mean and standard deviation values of PPT $\left(\mathrm{kg} / \mathrm{cm}^{2}\right)$ obtained for the craniocervical muscles in the EM (episodic migraine), CM (chronic migraine) and C (control) groups for both the right and left sides of the face.

\begin{tabular}{|c|c|c|c|c|c|c|}
\hline \multirow[b]{2}{*}{ Muscles } & \multicolumn{2}{|c|}{$\operatorname{EM}(n=15)$} & \multicolumn{2}{|c|}{$\mathrm{CM}(n=14)$} & \multicolumn{2}{|c|}{$C(n=15)$} \\
\hline & Right side & Left side & Right side & Left side & Right side & Left side \\
\hline Frontal & $2.20 \pm 0.64$ & $2.01 * \pm 0.67$ & $2.16^{*} \pm 0.52$ & $2.08^{*} \pm 0.69$ & $2.79 \pm 0.71$ & $2.85 \pm 0.71$ \\
\hline Anterior temporalis & $2.44 \pm 0.79$ & $2.39 \pm 0.73$ & $2.70 \pm 0.81$ & $2.30 \pm 0.61$ & $2.97 \pm 0.75$ & $2.80 \pm 0.67$ \\
\hline Medium temporalis & $2.54 \pm 0.75$ & $2.32 \pm 0.63$ & $2.62 \pm 0.76$ & $2.54 \pm 0.78$ & $2.89 \pm 0.66$ & $2.89 \pm 0.62$ \\
\hline Posterior temporalis & $2.72^{*} \pm 0.89$ & $2.60 * \pm 1.00$ & $3.17 \pm 0.79$ & $3.24 \pm 1.03$ & $3.36 \pm 0.72$ & $3.35 \pm 0.85$ \\
\hline Masseter - Origin & $1.57 \pm 0.54$ & $1.44 \pm 0.39$ & $1.82 \pm 0.45$ & $1.70 \pm 0.43$ & $1.99 \pm 0.55$ & $1.79 \pm 0.50$ \\
\hline Masseter - Belly & $1.63 \pm 0.46$ & $1.435 \pm 0.57$ & $1.88 \pm 0.43$ & $1.67 \pm 0.48$ & $2.04 \pm 0.45$ & $1.78 \pm 0.57$ \\
\hline Masseter - Insertion & $1.83 \pm 0.62$ & $1.58 \pm 0.48$ & $1.98 \pm 0.49$ & $1.79 \pm 0.52$ & $2.20 \pm 0.54$ & $2.00 \pm 0.46$ \\
\hline Trapezius - Insertion & $2.27 \pm 0.94$ & $2.29 \pm 0.70$ & $2.63 \pm 0.87$ & $2.46 \pm 0.81$ & $2.91 \pm 0.89$ & $2.89 \pm 0.74$ \\
\hline Trapezius - Upper & $2.69^{*} \pm 1.00$ & $2.54^{*} \pm 0.93$ & $2.96 \pm 0.95$ & $2.66^{*} \pm 0.84$ & $3.49 \pm 0.83$ & $3.32 \pm 0.97$ \\
\hline SCM Insertion & $2.11 \pm 0.71$ & $1.97 \pm 0.74$ & $2.23 \pm 0.45$ & $2.03 \pm 0.53$ & $2.48 \pm 0.64$ & $2.50 \pm 0.62$ \\
\hline
\end{tabular}

ANOVA (Duncan Post-hoc test) - $p<0.05$; *Difference in relation to control group in both right and left side; SCM: Sternocleidomastoid muscle; $n$ : sample size.

migraine, whereas significance of supraspinal facilitation is difficult to estimate ${ }^{28}$.

It's important to note that we have excluded in this study patients with diagnosis and/or complaint of other chronic musculoskeletal conditions, such as myofascial pain syndrome. However, it's possible that many patients could present latent trigger points (latent trigger points does not refer pain actively, but may do so when pressure or strain is applied to the musculoskeletal structure) that could influence migraine episodes but not deflagrate clinical symptoms verified during an anamnesis. Other explanation could be related to the frequency of myofascial pain episodes which could not characterize a chronic condition, but with a considerable frequency to enlarge peripheral nociceptive inputs.

If substantial differences were seen between $\mathrm{CM}$ and EM, it could be speculated that the greater the headache frequency more pronounced the central sensitization mechanism and the prolonged nociceptive inputs from trigger points could either contribute/onset ${ }^{28}$ or be a consequence of this process. In this way, PPT of craniocervical muscles could function as a marker of migraine chronification. By the other hand, our findings suggest that PPT reflects disease itself, not disease severity in terms of frequency.

However, it must be considered that the time of appearance of the disease was 15 and 22 years for EM and $\mathrm{CM}$, respectively (Table 1). In this way, the long time duration of the disease could contribute to the development of a chronic pain condition independently of migraine frequency, as suggest by the International Study of Pain (IASP) since to characterize chronic pain a temporal criteria of six months is generally used.

In disagreement with our results, Buchgreitz et al. ${ }^{4}$ reported an association between increased muscle ten- derness and headache chronification, but the authors did not evaluate episodic and chronic migraine patients. Our findings also disagree with a large populational study, where central sensitization was assessed using a validated questionnaire ${ }^{29}$. In that study, cutaneous allodynia was more common in CM than in EM. To justify the differences, we offer two non-mutually exclusive explanations. First, our study was conducted in the tertiary care, where EM sufferers are often severely affected, since the time of appearance of the disease is extensive in patients commonly attended in this kind of health service. This may have narrowed the differences between EM and CM. Additionally, in this populational study, central sensitization was measured but not peripheral contribution. Since PPT accounts for peripheral input and central sensitization, it may lack specificity (e.g. if episodic migraine is associated with more peripheral input than central facilitation and chronic migraine is characterized by the opposite, final results would be similar). Finally, we emphasize that our study is small and therefore no adjustments were conducted.

To the best of our knowledge, our study is the first to describe tenderness of craniocervical muscles in individuals with $\mathrm{CM}$ using pressure algometry in relation to healthy volunteers and comparing migraine and chronic migraine. In one of the few studies reported in the literature, patients were assessed by manual palpation, differences were presented for chronic tension-type headache and chronic migraine and a control group was not enrolled ${ }^{30,31}$.

Other studies investigated skin sensitivity in migraine patients in relation to healthy volunteers and in chronic versus episodic migraine patients ${ }^{12}$. However, such studies were conducted using Von Frey hairs and Quantitative Sensory Testing, in this way only skin sensitivity 
was verified and not the muscle tenderness, therefore not accounting for peripheral muscle contributions. Finally to the best of our knowledge, PPT values for masticatory and cervical sites as a function of headache status are missing.

The mechanism responsible for the transition from episodic to chronic pain are clinically very important for prevention and treatment strategies, but unfortunately poorly understood ${ }^{4}$. Differently from previous results ${ }^{8}$, our results failed to demonstrate a correlation between headache laterality and PPT values as observed by Fernandez-de- las-Peñas et al. ${ }^{9}$. This does not come to a surprise, since central sensitization accounts for bilateral hyperalgesia in unilateral pain syndromes ${ }^{30}$.

Our study has some limitations. First, this study was conducted in a clinic-based sample, second the sample size limits adjustments for confounders and third the absence of uniformity in pharmacologic treatment between patients.

Our data demonstrated that women with episodic and chronic migraine have reduced PPT values for several cranial and cervical muscles, as compared to controls. Future studies should better explore whether this parameter maps onto disease (EM and CM) or if a relationship with headache frequency was missed by our relatively small study. Studies should also assess if PPT values predict response to therapies.

\section{REFERENCES}

1. Lipton RB, Bigal ME, Diamond M, Freitag F, Reed ML, Stewart WF; AMPP Advisory Group. Migraine prevalence, disease burden, and the need for preventive therapy. Neurology 2007;68:343-349.

2. Haut SR, Bigal ME, Lipton RB. Chronic disorders with episodic manifestations: focus on epilepsy and migraine. Lancet Neurol 2006;5:148-157.

3. Silberstein SD, Lipton RB, Sliwinski M. Classification of daily and near-daily headaches: fiel trail of revised HIS criteria. Neurology 1996;47:871-875.

4. Buchgreitz, Lyngberg AC, Bendtsen L, Jensen R. Frequency of headache is related to sensitization: a population study. Pain 2006;123:19-27.

5. Burstein R. Deconstructing migraine headache into peripheral and central sensitization. Pain 2001;89:107-110.

6. Bigal ME, Lipton RB. Clinical course in migraine: conceptualizing migraine transformation. Neurology 2008;71:848-855.

7. Bevilaqua-Grossi D, Lipton RB, Napchan U, Grosberg B, Ashina S, Bigal ME. Temporomandibular disorders and cutaneous allodynia are associated in individuals with migraine. Cephalalgia 2009;30:425-432.

8. Fernández-de-las-Penas C, Cuadrado ML, Arendt-Nielsend L, Pareja JA. Side-to-side differences in pressure pain thresholds and pericranial muscle tenderness in strictly unilateral migraine. Eur J Neurol 2008;15:162-168.

9. Fernández-de-las-Peñas C, Madeleine P, Cuadrado ML, Ge HY, ArendtNielsen L, Pareja JA. Pressure pain sensitivity mapping of the temporalis muscle revealed bilateral pressure hyperalgesia in patients with strictly unilateral migraine. Cephalalgia 2009;29:670-676.
10. Fernandez-de-las-Peñas C, Cuadrado ML, Arendt-Nielsen L, Ge HY, Pareja JA. Increased pericranial tenderness, decreased pressure pain threshold, and headache clinical parameters in chronic tension-type headache patients. Clin J Pain 2007;23:346-352.

11. Bovim G. Cervicogenic headache, migraine and tension-type headache. Pressure pain threshold measurement. Pain 1992;51:169-173.

12. Jensen R, Rasmussen BK, Pedersen B, Olesen J. Muscle tenderness and pressure pain thresholds in headache: a population study. Pain 1993;52:193-199.

13. Kitaj MB, Klink M. Pain thresholds in daily transformed migraine versus episodic migraine headache patients. Headache 2005;45:992-998.

14. Headache Classification Subcommittee of the International Headache Society. The International Classification of Headache Disorders. 2nd edition. Cephalalgia 2004;24:9-160.

15. Bigal ME, Tepper SJ, Sheftell FD, Rapoport AM, Lipton RB. Chronic daily headache: correlation between the 2004 and the 1988 International Headache Society diagnostic criteria. Headache 2004;44:684-691.

16. Sandrini G, Antonaci F, Pucci E, Bono G, Nappi G. Comparative study with EMG, pressure algometry and manual palpation in tension-type headache and migraine. Cephalalgia 1994;14:451-457.

17. Chaves TC, Nagamine HM, Sousa LM, Oliveira AS, Bevilaqua-Grossi D. Intraand Inter agreement of pressure pain threshold for masticatory structures in children reporting orofcail pain relted to temporomandibular disorders and symptom-free children. J Orofacial Pain 2007;21:133-142.

18. Fischer AA. Pressure algometry over normal muscles. Standard values, validity and reproducibility of pressure threshold. Pain 1987;30:115-126.

19. Antonaci F, Sand T, Lucas GA. Pressure algometry in healthy subjects: interexaminer variability. Scand J Rehab Med 1998;30:3-8.

20. Dworkin SF, LeResche L. Research diagnostic criteria for temporomandibular disorders: Review, Criteria, Examinations and Specifications, Critique. J Temporomandibular Disord Facial Oral Pain 1992;6:300-355.

21. Ashina S, Babenko L, Jensen R, Ashina M, Magerl W, Bendtsen L. Increased muscular and cutaneous pain sensitivity in cephalic region in patients with chronic tension-type headache. Eur J Neurol 2005;12:543-549.

22. Isselée $H$, De Laat A, Lesaffre E, Lysens $R$. Short-term reproducibility of pressure pain thresholds in masseter and temporalis muscles of symptomfree subjects. Eur J Oral Sci 1997;105:583-587.

23. Fleiss JL, Levin B, Paik MC. Statistical methods for rates and proportions, Hoboken, New Jersey: John Wiley \& Sons, Inc., 2003

24. Fernández-de-las-Penas C, Cuadrado ML, Pareja JA. Myofascial trigger points, neck mobility and forward head posture in unilateral migraine. Cephalalgia 2006;26:1061-1070.

25. Treede RD, Rolke R, Andrews K, Margerl W. Pain elicited by blunt pressure: neurobiological basis and clinical relevance. Pain 2002;91:235-240.

26. Schürks M, Diener HC. Migraine, allodynia, and implications for treatment. Eur J Neurol 2008;15:1279-1285.

27. Herren-Gerber R, Weiss S, Arendt-Nielsen L, et al. Modulation of central hypersensitivity by nociceptive input in chronic pain after whiplash injury. Pain Med 2004;5:366-376.

28. Olesen J. Clinical and pathophysiological observations in migraine and tension-type headache explained by integration of vascular, supraspinal and myofascial inputs. Pain 1991;46:125-132.

29. Bigal ME, Ashina $S$, Burstein $R$, et al. Prevalence and characteristics of allodynia in headache sufferers: a population study. Neurology 2008;70: 1525-1533.

30. Mongini F, Rota E, Deregibus A, Mura F, Francia Germani A, Mongini T. A comparative analysis of personality profile and muscle tenderness between chronic migraine and chronic tension-type headache. Neurol Sci 2005;26:203-207.

31. Ge HY, Fernández-de-las-Peñas C, Madeleine P, Arendt-Nielsen L. Screening for myofascial trigger points bilaterally in the infraspinatus muscles in patients with unilateral shoulder pain. Eur J Pain 2008;12:859-865. 